\title{
Study of Serum Magnesium level and Atherosclerotic Changes in Patient on Maintenance Hemodialysis
}

\author{
Ahmed Rabie Alarbagy, Yassein Salah Yassein Mohamed' Mai Magdy Saad Zeid, \\ Heba EL Sayed Kasem Mohamed \\ Internal Medicine Department, Faculty of Medicine, Menoufia University, Menoufia, Egypt. \\ *Corresponding author: Mai Magdy Saad Zeid, Mobile: (+20)01022665962, E-mail: dr.mai.zeid@ gmail.com
}

\begin{abstract}
Background: Cardiovascular complications in dialysis patients focused on atherosclerosis. Serum magnesium has a role in cardiovascular complications in dialysis patients. Objectives: This study aimed to study the correlation between serum magnesium level and atherosclerotic changes in patients on maintenance hemodialysis.

Patients and methods: This prospective study included 60 patients with end-stage renal disease patients on maintenance HD, divided into Group I: (20 patients) with normal serum magnesium level (1.7 - $2.8 \mathrm{mg} / \mathrm{dl}$ ), Group II (20 patients) with low serum magnesium level $(<1.7 \mathrm{mg} / \mathrm{dl})$ and Group III (20 patients) with high serum magnesium level (> 2.8mg/dl.). Serum magnesium and lipid profile and intima-media thickness (IMT) of both common carotid arteries were measured. Results: Our results showed a significant negative association between level of serum $\mathrm{Mg}$ and IMT complex of both common carotid $(\mathrm{P}=0.045)$ and ischemic heart disease in the studied patients $(\mathrm{P}=0.012)$. The binary logistic regression for the predictors for IHD and CCA-IMT, we found that serum magnesium not an independent factor for atherosclerosis but we found that age and $\mathrm{DM}(\mathrm{P}<0.001)$ followed by cholesterol and triglycerides $(\mathrm{P}<0.05)$ are the most independent factors for CCA-IMT. Also, age (with OR: 95\% confidence Interval) $(0.145: 1.26-1.06)(\mathrm{P}<$ $0.001)$ and triglycerides $(1.02: 1.05-1.002),(\mathrm{P}<0.05)$ are the independent factors for IHD.
\end{abstract}

Conclusion: Our study revealed a significant inverse correlation between level of serum Mg and CCA-IMT and IHD in the studied HD patients. Thus, we suggest that regular screening of HD patients for serum Mg and CIMT with special consideration to diabetic and old patients is recommended to stratify their CV risk.

Keywords: End stage renal disease, Magnesium, Atherosclerosis, Intima media thickness.

\section{INTRODUCTION}

CKD is a worldwide public health issue and has been identified as a major risk factor for atherosclerotic CVD ${ }^{(\mathbf{1})}$. Cardiovascular diseases affect the morbidity and mortality of CKD patients in the early stages of the disease ${ }^{(2)}$. Thus, CKD can be defined as a pro-atherogenic state ${ }^{(3)}$. The atheroma-promoting CKD factors are dyslipidemia, impaired HDL function and disrupted reverse cholesterol transport ${ }^{(4)}$. Factors contributing to this atherogenic environment include the presence of uremic toxins, persistent inflammation and oxidative stress ${ }^{(5)}$.

CKD itself is an independent risk factor for CVD; both traditional and non-traditional risk factors for CVD exist in CKD patients ${ }^{(6)}$. Traditional risk factors are found in both the CKD and non-CKD population ${ }^{(7)}$. Nontraditional risk factors may result from or be worsened by CKD and negatively influences the cardiovascular system in the CKD population ${ }^{\left({ }^{8}\right)}$. These include oxidative stress, inflammation, lipids metabolism, calcium and phosphate (9). In early stages of CKD patients mainly have endothelial dysfunction, which is a predictor of CVD ${ }^{(10)}$. There is a common association between CKD and alterations in lipoprotein structure and function, as reduced high-density lipoprotein cholesterol, increased intermediate-density lipoprotein, increased proatherogenic lipid particles ${ }^{(11)}$. To diagnose of CVDs, especially atherosclerotic changes in patients with HD noninvasive tests are necessary ${ }^{(\mathbf{1 0})}$. IMT can be predict survival outcomes in patients with $\mathrm{HD}^{(\mathbf{1 2})}$. B-mode ultrasound imaging is one of the tools used for the diagnosis of atherosclerotic Changes ${ }^{(\mathbf{1 3})}$. $\mathrm{Mg}$ is the second most abundant intracellular cation and it plays a key role in a wide range of cellular functions. End-stage renal disease (ESRD) patients have usually normal serum levels of $\mathrm{Mg}$ and sometimes even low serum $\mathrm{Mg}$ concentration (hypomagnesaemia) (14). In ESRD patient's hypomagnesaemia may result from different medications, proton-pump inhibitors, aminoglycoside antibiotics and decreased intestinal $\mathrm{Mg}$ absorption probably due to a deficiency of active vitamin $\mathrm{D}^{(\mathbf{1 5})}$.

Recently it was found that hypomagnesaemia has been associated with inflammation and disturbances in vascular tone regulation and endothelial function, which contribute to atherosclerosis development and progression (16). So, the aim of our study was to study the correlation between serum Magnesium level and atherosclerotic changes in patient on maintenance hemodialysis.

\section{PATIENTS AND METHODS}

Our study included 60 patients with ESRD on maintenance HD. They were divided into three main groups, Group (I): included 20 patients with normal serum magnesium level (1.7 -2.8 mg/dl), Group (II): included 20 patients with low serum magnesium level less than 1.7 $\mathrm{mg} / \mathrm{dl}$ and Group (III): included 20 patients with high serum magnesium level more than $2.8 \mathrm{mg} / \mathrm{dl}$. Patients of acute renal failure, chronic liver disease, taking 
magnesium containing drugs or/ drugs that affect level of lipid and lipoproteins and patient with body mass index more than $24.9 \mathrm{~kg} / \mathrm{m} 2$ were excluded from the study. All HD patients were on 4 hrs dialysis, three times a week, using filters of $1.3-1.7 \mathrm{~m}^{2}$ surface area and dialyzer with bicarbonate based dialysate. The composition of the dialysate was sodium: $140.6 \mathrm{mmol} / \mathrm{l}$, potassium: 2 mmol/l, bicarbonate: $32 \mathrm{mmol} / \mathrm{l}$, calcium: $1.5 \mathrm{mmol} / \mathrm{l}$. Blood flow rate was $250-300 \mathrm{ml} / \mathrm{min}$ and dialysate flow rate was $500-600 \mathrm{ml} / \mathrm{min}$ on Fresenius (4008B) dialysis machine. Patients' clinical and demographic characteristics and routine laboratory parameters were recorded and analyzed including age, gender, BMI, associated comorbidities as DM, HTN, and ischemic heart disease. Duration of hemodialysis and adequacy of hemodialysis was determined by urea reduction ratio \& $\mathrm{KT} / \mathrm{V}$. Laboratory data were collected including complete blood picture using sysmex Kx-21 automated hematology analyzer (sysmex corporation, Japan). Lipid profile (cholesterol, triglyceride, LDL and HDL) using the open system auto analyzer synchron CXS (Beckman, USA) and electrolytes (sodium, potassium, calcium, phosphorus) and serum magnesium (with reference value of $1.7-2.8$ $\mathrm{mg} / \mathrm{dl}$ ) were measured by Beckmann synchron Au 860 (USA). Doppler ultrasound on common carotid arteries was done for all patients to assess IMT complex of both common carotid arteries as marker for atherosclerotic changes by a real-time high-resolution B-mode ultrasonography. Normal value of IMT is less than 1.0 $\mathrm{mm}$.

Ethical approval: This prospective randomized study was approved from the Ethical Committee, Faculty of Medicine, Menoufia University and informed consent was obtained from all study participants.

\section{Statistical analysis}

Statistical analysis was carried out using statistical package for social science, version 17 program on Windows 7 (SPSS Inc., Chicago, Illinois, USA). Qualitative data were represented in the form of number and percentage, whereas quantitative data were represented in the form of mean \pm SD. The KolmogorovSmirnov test was used to test normality of quantitative data. The $\mathrm{X}^{2}$, one-way analysis of variance, and KruskalWallis tests were used to compare groups. Spearman's rank correlation test was used to study correlation between parameters. Results were considered significant if $P$ value was less than or equal to 0.05 . linear regression was carried out for independent factors for IMT and IHD.

\section{RESULTS}

Our study included 80 patients, which were divided into 3 groups. Group (I): with normal serum $\mathrm{Mg}$ (12 Males\& 8 Females) with a mean age of $(49.7 \pm 14.5$ years), Group (II): with low serum Mg (9 Males \& 11 Females) with a mean age of $(55.9 \pm 14.8$ years $)$ and Group (III): with high serum Mg (11 Males \& 9 Females) with a mean age of $(58.9 \pm 11.2$ years $)$. There was no statistical significance between them as regards age and sex indicating matching between the groups. Regarding the associated comorbidities, there was highly significant difference between the three groups as regards IHD that was more evident in group II $(\mathrm{P}=0.00)$. The difference between the three groups was statistically significant as regards $\mathrm{BMI}(\mathrm{P}=0.03)$ and dry weight $(\mathrm{P}=0.003)$ as shown in table (1).

Table (1): Comparison between the studied groups as regarding demographic data

\begin{tabular}{|c|c|c|c|c|c|}
\hline & & \multicolumn{3}{|c|}{ Studied group $N=60$} & \multirow{3}{*}{$\begin{array}{c}P \\
\text { value }\end{array}$} \\
\hline & & Group (I) & Group (II) & Group (III) & \\
\hline & & $(\mathrm{No}=\mathbf{2 0})$ & $(\mathrm{No}=20)$ & $(\mathrm{N} 0=20)$ & \\
\hline \multirow{2}{*}{ Gender } & Male & $12(60 \%)$ & $9(45 \%)$ & $11(55 \%)$ & 0.62 \\
\hline & Female & $8(40 \%)$ & $11(55 \%)$ & $9(45 \%)$ & \\
\hline \multirow{3}{*}{ Comorbidities } & DM & & & & \\
\hline & Yes & $2(10 \%)$ & $3(15 \%)$ & $3(15 \%)$ & 1 \\
\hline & No & $18(90 \%)$ & $17(85 \%)$ & $17(85 \%)$ & \\
\hline \multirow{2}{*}{ HTN } & Yes & $13(65 \%)$ & $14(70 \%)$ & $14(70 \%)$ & 1 \\
\hline & No & $7(35 \%)$ & $7(30 \%)$ & $19(30 \%)$ & \\
\hline \multirow{2}{*}{ Smoking } & Yes & $1(5 \%)$ & $5(25 \%)$ & $3(15 \%)$ & 0.2 \\
\hline & No & $19(95 \%)$ & $15(75 \%)$ & $17(85 \%)$ & \\
\hline \multirow{2}{*}{ IHD } & Yes & $1(5 \%)$ & $16(80 \%)$ & $8(40 \%)$ & $0.00^{* *}$ \\
\hline & No & $19(95 \%)$ & $4(20 \%)$ & $12(60 \%)$ & \\
\hline Age (years) & Mean \pm SD & $49.7 \pm 14.5$ & $55.9 \pm 14.8$ & $58.9 \pm 11.2$ & 0.1 \\
\hline $\begin{array}{l}\text { Duration of hemodialysis } \\
\text { (years) }\end{array}$ & Mean \pm SD & $4.62 \pm 4.1$ & $3.3 \pm 3.1$ & $5.9 \pm 3.8$ & 0.14 \\
\hline BMI & Mean \pm SD & $25.7 \pm 2.10$ & $21.03 \pm 1.77$ & $22.58 \pm 1.96$ & $0.03 *$ \\
\hline Dry body weight (kg) & Mean \pm SD & $63.7 \pm 5.52$ & $59.5 \pm 3.02$ & $62.6 \pm 5.25$ & $0.003^{*}$ \\
\hline
\end{tabular}

*: Statistically significant at $P$ value $<0.05$, **: Statistically highly significant at $P$ value $<0.001$ DM: diabetes mellitus, HTN: hypertension, IHD: ischemic heart disease, BMI: body mass index

There was no statistical difference as regards hemoglobin, electrolyte (sodium, potassium, calcium and phosphorus), intact PTH and adequacy of dialysis by URR and KT/V (Table 2). 
Table (2): Comparison between the studied groups as regarding laboratory data and adequacy of hemodialysis

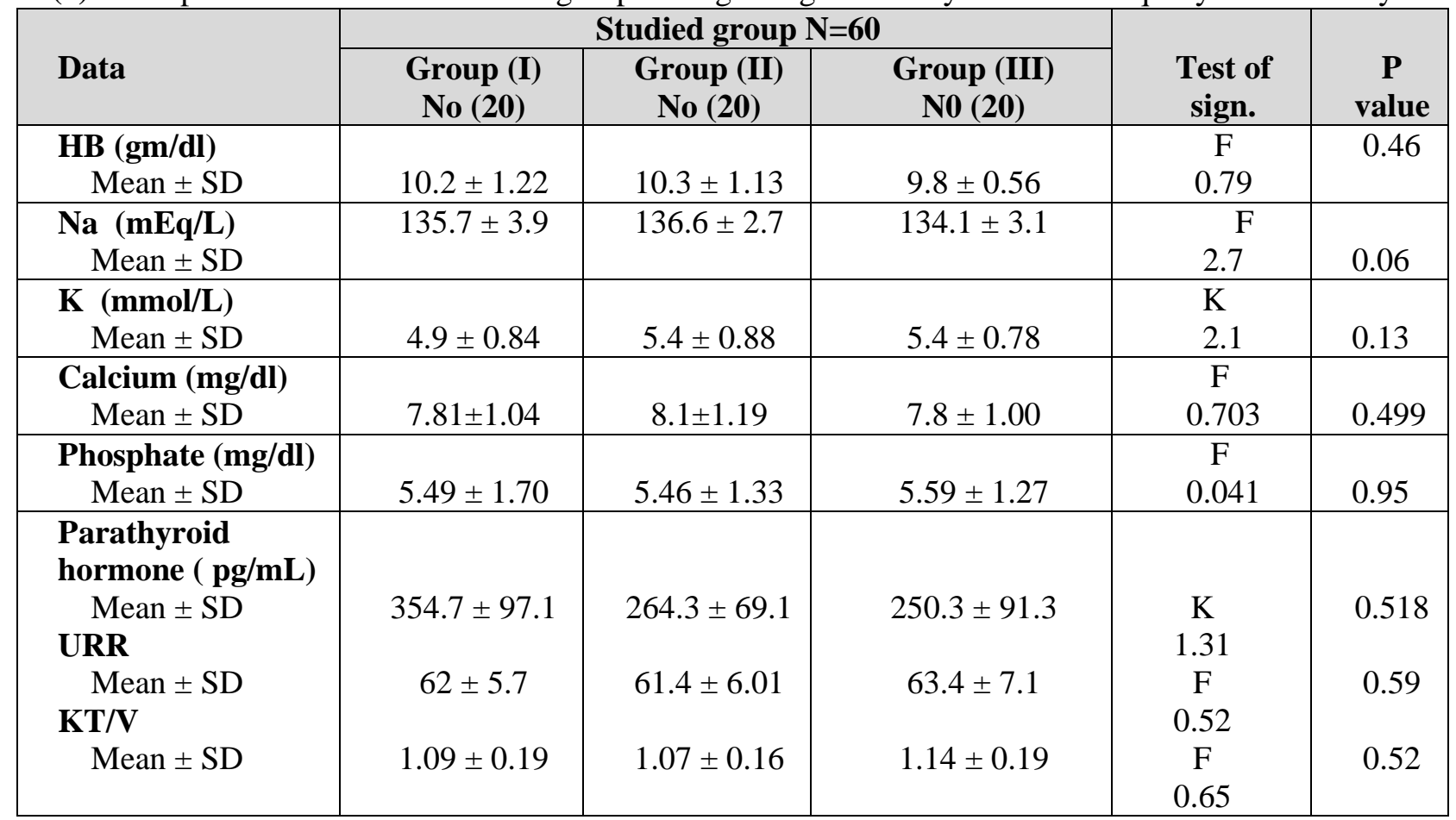

HB: hemoglobin, Na: sodium, K: potassium, URR: urea reduction ratio. $\quad F=$ ANOVA $F$ test, $K=$ Kruskal-Wallis test

Concerning cholesterol, triglyceride and LDL, they showed statistically significant difference between the patients with normal Mg level and those with hypomagnesemia $(\mathrm{P} 1=0.001)$. Moreover, cholesterol, HDL and LDL showed statistically significant difference between the patients with hypermagnesemia and those with hypomagnesemia $(\mathrm{P} 1=0.001)$ and CCA-IMT was more evident in patients with hypomagnesemia than other group with normal $\mathrm{Mg}$ level $(\mathrm{P}=0.001)$ as shown in table (3).

Table (3): Comparison between the studied groups regarding lipid profile and CCA

\begin{tabular}{|c|c|c|c|c|c|c|}
\hline \multirow[t]{2}{*}{ Data } & \multicolumn{3}{|c|}{ Studied group $\mathbf{N}=60$} & \multirow[b]{2}{*}{$\begin{array}{c}\text { Test of } \\
\text { sign. }\end{array}$} & \multirow[b]{2}{*}{$P$ value } & \multirow[b]{2}{*}{ Post Hoc } \\
\hline & $\begin{array}{c}\text { Group (I) } \\
(\text { No }=20) \\
\end{array}$ & $\begin{array}{c}\text { Group (II) } \\
(\text { No=20) }\end{array}$ & $\begin{array}{c}\text { Group (III) } \\
(\text { N0=20) }\end{array}$ & & & \\
\hline $\begin{array}{l}\text { Cholesterol } \\
(\mathbf{m g} / \mathbf{d l}) \\
\text { Mean } \pm \text { SD }\end{array}$ & $165.4 \pm 24.8$ & $221 \pm 31.1$ & $178.7 \pm 15.04$ & $\begin{array}{c}\mathrm{F} \\
27.8\end{array}$ & $\leq 0.001 * *$ & $\begin{array}{l}\mathbf{P 1}=0.001 \\
\text { P2 }=0.09 \\
\mathbf{P 3}=0.001\end{array}$ \\
\hline $\begin{array}{l}\text { Triglyceride } \\
(\mathbf{m g} / \mathbf{d l}) \\
\text { Mean } \pm \text { SD }\end{array}$ & $102.7 \pm 20.5$ & $130.1 \pm 35.5$ & $117 \pm 13.2$ & $\begin{array}{c}F \\
6.04\end{array}$ & $0.004 *$ & $\begin{array}{l}\mathbf{P 1}=0.001 \\
\mathrm{P} 2=0.07 \\
\mathrm{P} 3=0.10\end{array}$ \\
\hline $\begin{array}{l}\text { HDL }(\mathbf{m g} / \mathbf{d l}) \\
\text { Mean } \pm \text { SD }\end{array}$ & $48.4 \pm 18.7$ & $47.4 \pm 13.1$ & $65.5 \pm 14.1$ & $\begin{array}{c}F \\
8.6\end{array}$ & $0.001 * *$ & $\begin{array}{l}\mathrm{P} 1=0.839 \\
\mathbf{P 2}=0.001 \\
\mathbf{P 3}=0.001\end{array}$ \\
\hline $\begin{array}{l}\text { LDL }(\mathbf{m g} / \mathbf{d l}) \\
\text { Mean } \pm \text { SD }\end{array}$ & $96.5 \pm 17.9$ & $127.9 \pm 31.9$ & $86.5 \pm 9.14$ & $\begin{array}{c}\mathrm{F} \\
19.6\end{array}$ & $\leq 0.001 * *$ & $\begin{array}{l}\mathbf{P 1}=0.001 \\
\text { P2 }=0.151 \\
\mathbf{P 3}=0.001\end{array}$ \\
\hline $\begin{array}{l}\text { CCA-IMT } \\
\text { Mean } \pm \text { SD }\end{array}$ & $0.753 \pm 0.135$ & $1.02 \pm 0.22$ & $0.925 \pm 0.148$ & $\begin{array}{c}\mathrm{F} \\
12.5\end{array}$ & $0.001 * *$ & $\begin{array}{l}\mathbf{P 1}=0.001 \\
\mathbf{P 2}=0.003 \\
\text { P3 }=0.07\end{array}$ \\
\hline
\end{tabular}

*: Statistically significant at $\mathrm{P}$ value $<0.05, * *$ : Statistically highly significant at $\mathrm{P}$ value $<0.001, \mathrm{~F}=\mathrm{ANOVA} \mathrm{F}$ test $\mathrm{P} 1=$ Compare cholesterol between normal magnesium level cases and hypomagnesemia cases P2=Compare cholesterol between normal magnesium level cases and hypermagnesemia cases P3=Compare cholesterol between hypomagnesemia cases and hypermagnesemia cases

HDL: high density lipoprotein, LDL: low density lipoprotein, CCA: common carotid artery, IMT: intima media thickness.

The hypomagnesemia had a high significant correlation with the pro-atherosclerotic factors as cholesterol "figure 1", HDL "figure 2" and LDL level "figure 3" $(\mathrm{P}=0.001)$. Also, a significant negative association with the presence of ischemic heart diseases "figure 5" and Doppler ultrasonographic changes of common carotid arteries in form of intima media thickness "figure 3 " in our studied groups $(\mathrm{P}<0.05)$ (Table 4$).$ 
Table (4): Correlations between level of serum magnesium among studied patients and other indices

\begin{tabular}{l|c|c|}
\hline \multirow{2}{*}{ Age (years) } & \multicolumn{2}{|c|}{ Level of serum magnesium } \\
\cline { 2 - 2 } Duration of hemodialysis (years) & $\mathrm{R}$ & $\mathrm{P}$-value \\
\cline { 2 - 2 } Cholesterol (mg/dl) & 0.01 & 0.90 \\
Triglyceride (mg/dl) & 0.214 & 0.100 \\
\cline { 2 - 2 } HDL (mg/dl) & -0.471 & $0.001^{* *}$ \\
\cline { 2 - 2 } LDL (mg/dl) & -0.225 & 0.08 \\
Calcium (mg/dl) & 0.459 & $0.001^{* *}$ \\
Phosphate (mg/dl) & -0.575 & $0.001^{* *}$ \\
Parathyroid hormone (Pg/ml) & 0.156 & 0.235 \\
CCA-IMT & 0.06 & 0.602 \\
IHD & 0.04 & 0.782 \\
\cline { 2 - 2 } & -0.259 & $0.045^{*}$ \\
\cline { 2 - 2 } & -0.321 & $0.012^{*}$ \\
\hline
\end{tabular}

*: Statistically significant at $P$ value $<0.05, * *$ : Statistically highly significant at $P$ value $<0.001$

HDL: high density lipoprotein, LDL: low density lipoprotein, CCA: common carotid artery, IMT: intima media thickness, IHD: ischemic heart disease Figure (1): Relation between magnesium with cholesterol.

Figure (1): Relation between magnesium with cholesterol

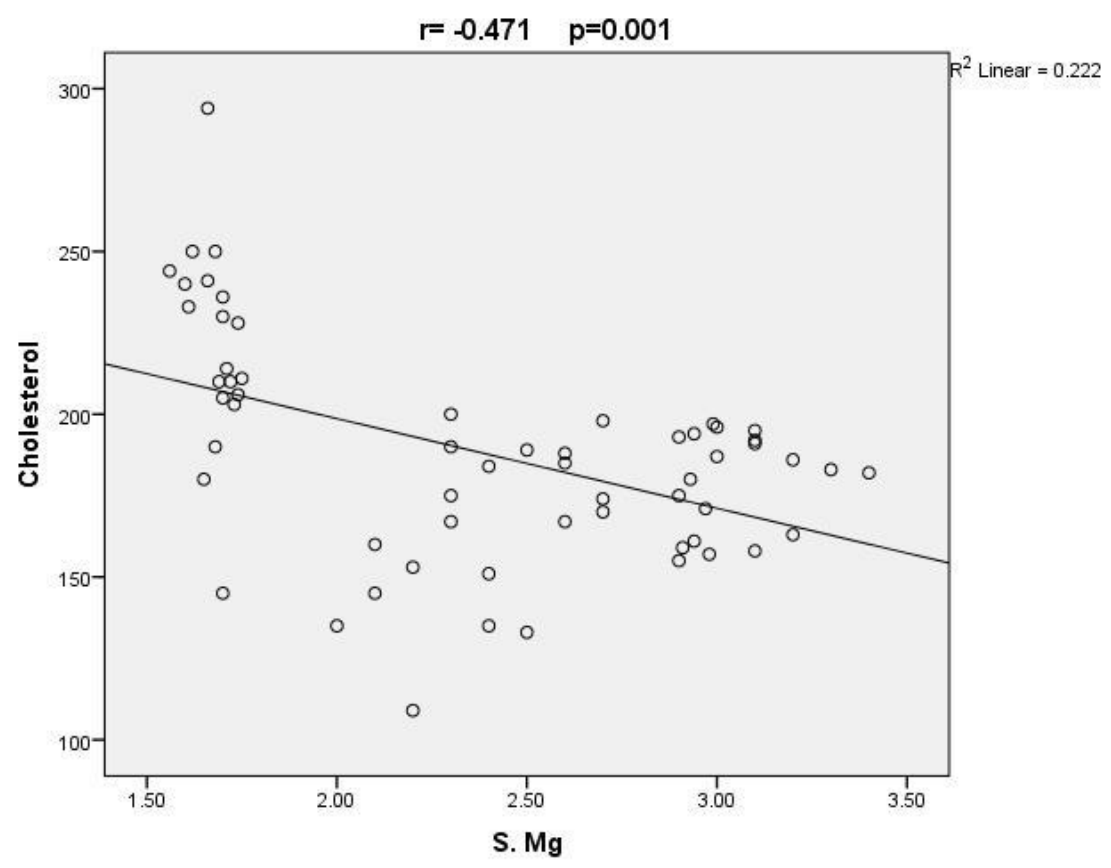




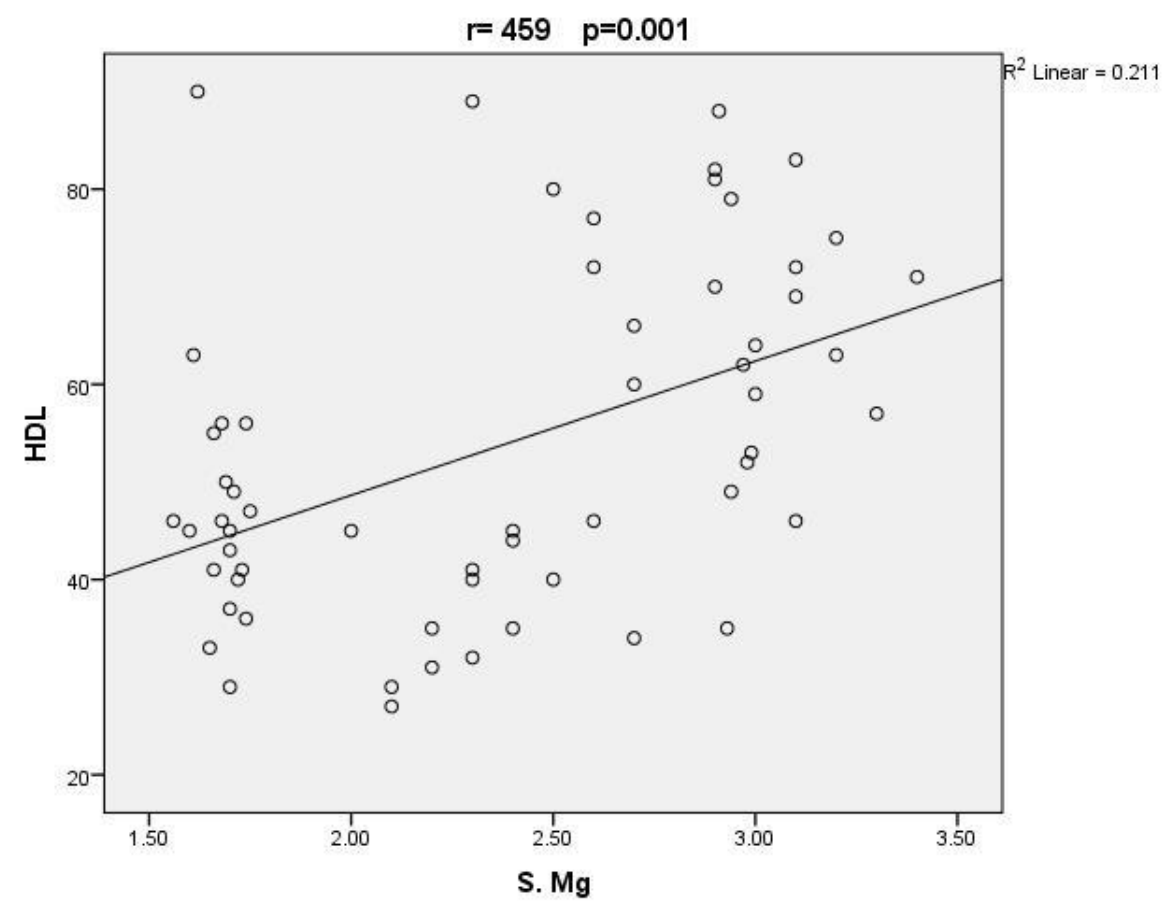

Figure (2): Relation between serum magnesium with HDL

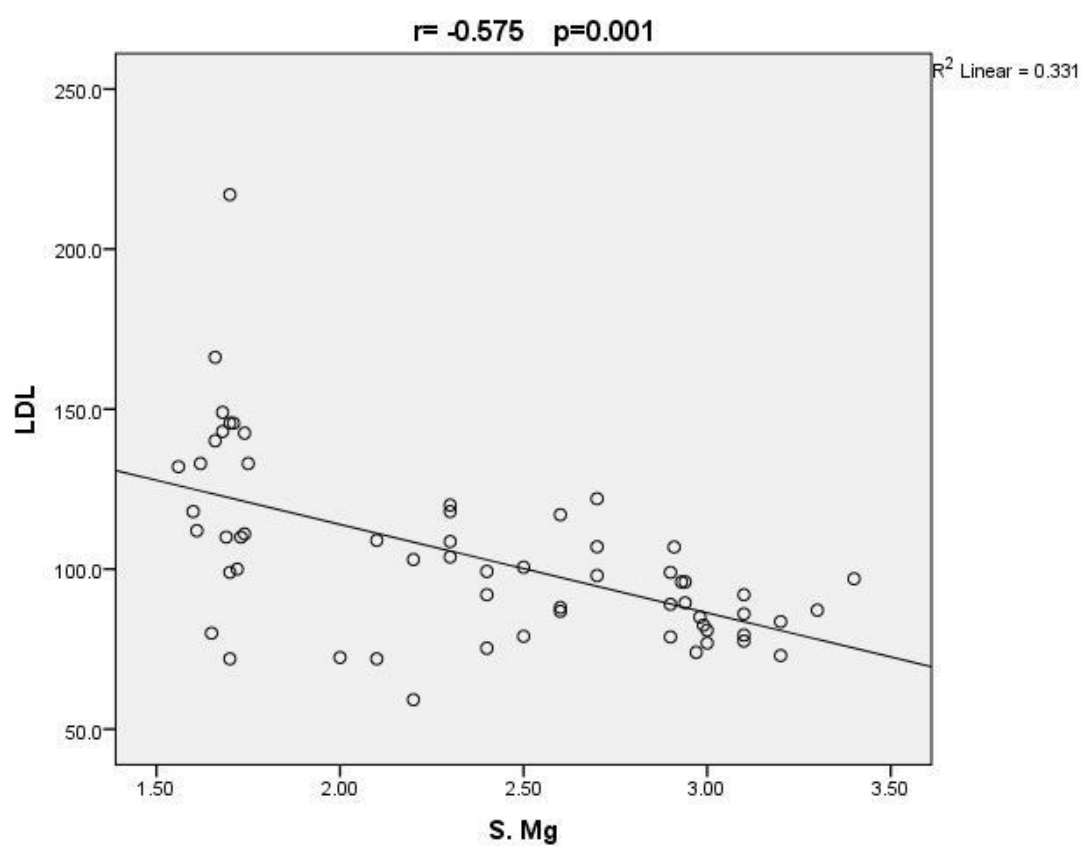

Figure (3): Relation between serum magnesium with LDL 


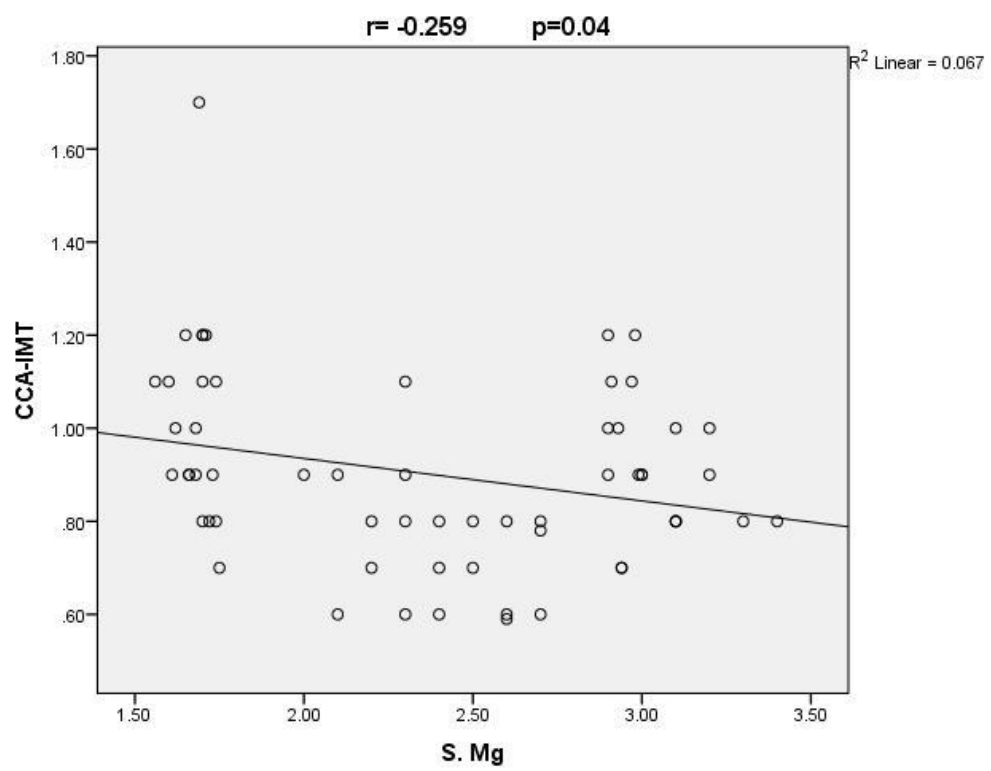

Figure (4): relation between serum magnesium with CCA-IMT

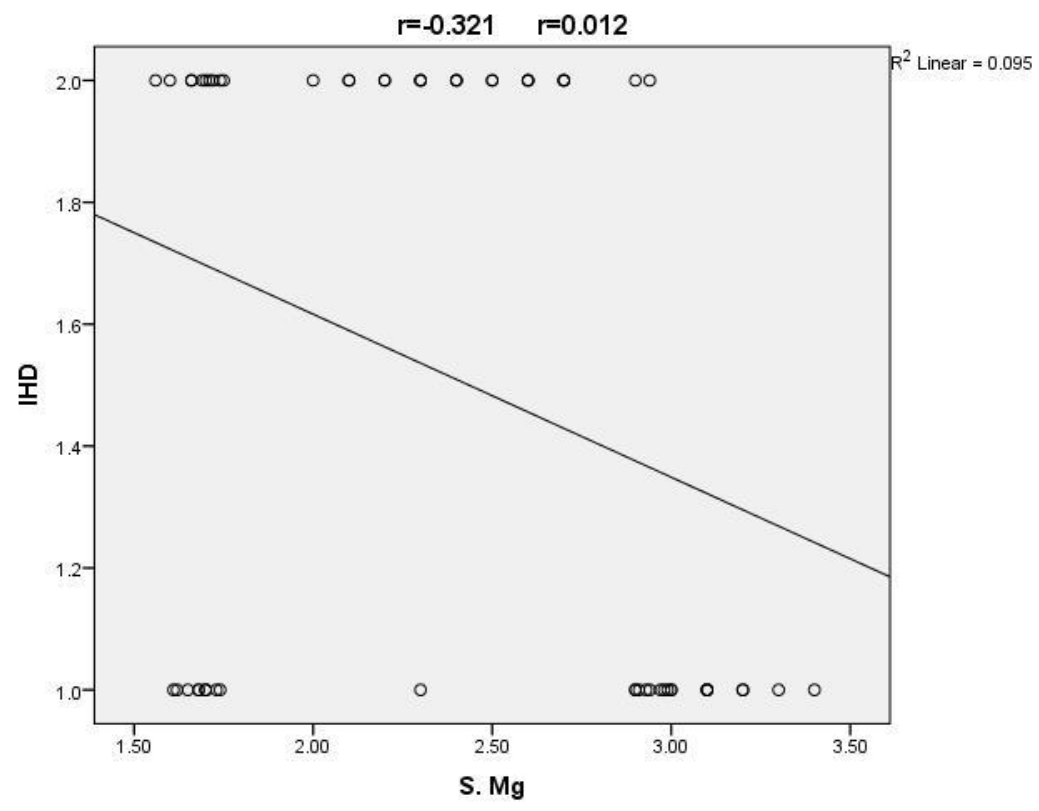

Figure (5): Relation between serum magnesium with IHD.

As regards the binary logistic regression for the predictors for IHD and CCA-IMT, we found that serum magnesium was not an independent factor for atherosclerosis but we found that age and DM $(\mathrm{P}<0.001)$ followed by cholesterol and triglycerides $(\mathrm{P}<0.05)$ were the most independent factors for CCA-IMT (Table 5).

Table (5): Linear regression for independent factors for CIMT

\begin{tabular}{|l|c|c|c|}
\hline Predictors & Beta $(\boldsymbol{\beta})$ & t & P value \\
\hline Age (years) & 0.56 & 5.22 & $0.001^{* *}$ \\
\hline Serum magnesium (mg/dl) & -0.08 & -0.63 & 0.52 \\
\hline Cholesterol (mg/dl) & 0.27 & 2.16 & $0.03^{*}$ \\
\hline Triglycerides (mg/dl) & 0.27 & 2.17 & $0.03^{*}$ \\
\hline DM & -0.19 & -1.48 & $0.001^{* *}$ \\
\hline
\end{tabular}

*: Statistically significant at $P$ value $<0.05, * *$ : Statistically highly significant at $P$ value $<0.001$

DM: diabetes mellitus

Also, age (OR: 95\% confidence Interval) $(0.145: 1.26-1.06)(\mathrm{P}<0.001)$ and triglycerides $(1.02: 1.05-1.002)$ $(\mathrm{P}<0.05)$ were the independent factors for IHD (Table 6). 
Table (6): Binary logistic regression for independent factors for IHD

\begin{tabular}{|l|c|c|c|}
\hline Predictors & Wald & Sig. & OR (95\% confidence Interval) \\
\hline Age & 10.9 & $0.001^{* *}$ & $\mathbf{0 . 1 4 5}(\mathbf{1 . 2 6 - 1 . 0 6})$ \\
\hline Serum magnesium (mg/dl) & 1.11 & 0.29 & $\mathbf{0 . 7 9}(\mathbf{1 . 2 2 - 0 . 5 1})$ \\
\hline Cholesterol (mg/dl) & 0.29 & 0.58 & $\mathbf{0 . 9 9}(\mathbf{1 . 0 1 - 0 . 9 7 )}$ \\
\hline Triglycerides (mg/dl) & 4.37 & $0.03^{*}$ & $\mathbf{1 . 0 2}(\mathbf{1 . 0 5 - 1 . 0 0 2})$ \\
\hline LDL (mg/dl) & 1.04 & 0.30 & $\mathbf{1 . 0 1}(\mathbf{1 . 0 2 - 0 . 9 9})$ \\
\hline
\end{tabular}

*: Statistically significant at $P$ value $<0.05, * *$ : Statistically highly significant at $P$ value $<0.001$

LDL: low density lipoprotein

\section{DISCUSSION}

Magnesium along with potassium are the dominant intracellular cations ${ }^{(\mathbf{1 7})}$. $\mathrm{Mg}$ plays a pivotal role in many biological processes such as enzymatic reactions, gene transcription, bone remodeling and

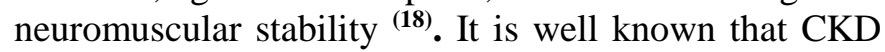
patients with or without HD show a higher incidence of death and $\mathrm{CV}$ diseases ${ }^{(10)}$. This, in addition to the traditional and CKD-associated CV risk factors, can be partially attributable, to the accelerated atherosclerosis and increased cardiovascular events have been extensively documented in patients with (ESRD) ${ }^{(19)}$. Patients with ESRD have classical cardiovascular risk factors such as age, male gender, smoking, hypertension, dyslipidemia and diabetes ${ }^{(20)}$. $\mathrm{Mg}$ has role in the electrical stability and energy balance of cardiomyocytes where hypomagnesemia has been associated with atrial and ventricular arrhythmias and might be a risk factor for sudden cardiac death (SCD) ${ }^{(21)}$. Hypomagnesemia has been associated with inflammation and disturbances in the vascular tone regulation and endothelial function ${ }^{(22)}$. These mechanisms are thought to contribute to the development and progression of atherosclerosis, potentially worsening coronary heart disease ${ }^{(\mathbf{1 6})}$. Mg also reduces triglycerides and LDL and increases HDL levels, so the aim of our study was to study the correlation between serum magnesium level and atherosclerotic changes in patient on maintenance hemodialysis.

Our study showed that the pro-atherosclerotic factors such as cholesterol, triglyceride and LDL levels were higher in patients with hypomagnesaemia than other groups. While, HDL level is low with significant negative correlation between hypomagnesaemia and cholesterol, triglyceride and LDL. While, no statistical significant correlations were found with gender, DM, HTN, smoking, age, duration of hemodialysis, electrolytes (calcium and phosphate) and parathyroid hormone level. In addition, magnesium level did not affect the adequacy of hemodialysis. This agrees with results of Gupta et al. ${ }^{(23)}$ that showed a high significant statistical difference between study groups regarding LDL, HDL, TG and cholesterol.

In our study, the CCA-IMT by B-mode ultrasound showed atherosclerotic changes in patients with hypomagnesaemia than other groups and a significant negative association with the presence of ischemic heart diseases and intima media thickness. Our results agree with other studies that reported the inverse relationship between $\mathrm{Mg}$ level and CCA-IMT ${ }^{(24)}$.
Tzanakis et al. ${ }^{(13)}$ concluded that there is a strong negative association of serum magnesium with intimamedia complex thickness of common carotid arteries in hemodialysis patients. Tony et al. ${ }^{(25)}$ showed that high serum LP-a level and Mg depletion in CKD patients on maintenance HD displayed a high frequency of abnormal electrocardiographic findings, including a high prevalence of patients with prolonged QT interval. Liu et al. ${ }^{(26)}$ showed that lower serum Mg was associated with risk factors for cardiovascular disease in HD patients, such as greater incidence of IDH, poorer HD adequacy, deteriorating calcium-phosphate metabolism, inflammation and CIMT. Ari et al. ${ }^{(27)}$ showed that serum level of magnesium and other trace elements are associated with carotid atherosclerosis in HD patients and there was a significant positive correlation between serum levels of magnesium and CIMT and this disagrees with our study.

Concerning the binary logistic regression for the predictors for IHD and CCA-IMT, we found that serum magnesium was not an independent factor for atherosclerosis but we found that age and DM followed by cholesterol and triglycerides were the most independent factors for CCA-IMT. Kuswardhani $\boldsymbol{e t}$ al. (5) results showed that in the multiple linear regression analysis, only age consistently had a role in determining the CIMT value. Falaknazi et al. ${ }^{(28)}$ showed that there were significant positive correlations between CIMT, age and dialysis duration. The age and triglycerides in our study were the independent factors for IHD. Zhou et al. (29) results showed that there was a significant positive correlation between IHD and age, level of triglyceride and cholesterol.

Our study showed that age was the independent factor for atherosclerosis in ESRD patients while hypomagnesaemia correlated with the metabolic profile of the patients as cholesterol, triglyceride, HDL and LDL with the presence of DM contribute as a risk factor for atherosclerosis. The limitation of our study was a small sample size and we recommended more researches on the effect of magnesium level on morbidity and mortality of hemodialysis patients.

\section{CONCLUSIONS}

Our study revealed a significant inverse correlation between level of serum $\mathrm{Mg}$ and CCA-IMT and IHD in the studied HD patients. Thus, we suggest that regular screening of HD patients for serum $\mathrm{Mg}$ and CIMT with 
special consideration to diabetic and old patients is recommended to stratify their $\mathrm{CV}$ risk.

\section{- No Funding}

- No conflict of interest

\section{REFERENCES}

1. Tonelli M, Muntner P, Lloyd A et al. (2012): Alberta Kidney Disease Network. Risk of coronary events in people with chronic kidney disease compared with those with diabetes: A population-level cohort study. Lancet, 380 (9844): 807-814.

2. Bansal N (2012): Clinically silent myocardial infarctions in the CKD community. Nephrol Dial Transplant, 27 (9): 3387-3391.

3. Wanner C, Tonelli M (2014): Kidney Disease: Improving Global Outcomes Lipid Guideline Development Work Group Members. KDIGO Clinical Practice Guideline for Lipid Management in CKD: summary of recommendation statements and clinical approach to the patient. Kidney Int., 85 (6): 1303-1309.

4. Archakova T, Nedosugova $L$ (2018): Risk factors for atherosclerosis and vascular calcification in patients with type 2 diabetes on long-term hemodialysis. Vessel Plus, 2: 34-37.

5. Kuswardhani R, Kandarini Y, Martadiani E et al. (2019): Factors associated with carotid intima-media thickness in patients on maintenance hemodialysis International Journal of General Medicine. Int J Gen Med., 12: $1-6$

6. Kalil R, Wang J, de Boer I et al. (2015): Effect of extended-release niacin on cardiovascular events and kidney function in chronic kidney disease: a post hoc analysis of the AIM-HIGH trial. Kidney Int., 87 (6): 12507.

7. Kato K, Yonetsu T, Jia H et al. (2013): Non-culprit coronary plaque characteristics of chronic kidney disease. Circ Cardiovasc Imaging, 6 (3): 448-456.

8. Williams $P$, Zhao $X$, Marcovina $S$ et al. (2014): Comparison of four methods of analysis of lipoprotein particle subfractions for their association with angiographic progression of coronary artery disease. Atherosclerosis, 233 (2): 713-720.

9. Reiss A, Voloshyna I, DeLeon J et al. (2015): Cholesterol Metabolism in CKD. Am J Kidney Dis., 66 (6): 1071-1082.

10. Chu M, Wang A, Chan I et al. (2012): Serum smalldense LDL abnormalities in chronic renal disease patients. Br J Biomed Sci., 69 (3): 99-102.

11. Rysz J, Gluba-Brzózka A, Banach $M$ et al. (2015): Should we use statins in all patients with chronic kidney disease without dialysis therapy? The current state of knowledge. Int Urol Nephrol., 47 (5): 805-813.

12. Abbasi R, Abbaszadeh H, Rokni-Yazdi H et al. (2016): Carotid intima-media thickness as a marker of atherosclerosis in hemodialysis patients. Indian $\mathbf{J}$ Nephrol., 26 (2): 97.

13. Tzanakis L, Virvidakis K, Tsomi A et al. (2004): Intraand extracellular magnesium levels and atheromatosis in hemodialysis patients. Magnes Res., 17 (2): 102-8.
14. Alhosaini M, Walter S, Singh $S$ et al. (2014): Hypomagnesaemia in hemodialysis patients: role of proton pump inhibitors. Am J Nephrol., 39: 204-209

15. Courivaud C, Davenport A (2014): Magnesium and risk of all causes and cardiac mortality in hemodialysis patients. Kidney Int., 85 (1): 17-20.

16. Massy A, Drueke B (2012): Magnesium and outcomes in patients with chronic kidney disease: focus on vascular calcification, atherosclerosis and survival. Clin Kidney J., 5 (1): 52-61.

17. Kieboom B, Niemeijer $M$, Leening $M$ et al. (2016): Serum Magnesium and the Risk of Death from Coronary heart Disease and Sudden Cardiac Death. J Am Heart Assoc., 4: 1-11.

18. Kumar P, Clark M (2102): Disorders of Magnesium concentration. Clinical Medicine, 2 (8): 656-657

19. Shechter M (2010): Magnesium and cardiovascular system. Magnes Res., 23: 60-72.

20. Santoro A, Mandreoli M (2014): Chronic Renal disease and Risk of cardiovascular Morbidity -Mortality. Kidney Blood Press Res., 39: 142-146

21. Reffelmann T, Ittermann T, Dörr M et al. (2019): Low serum magnesium concentrations predict cardiovascular and all-cause mortality. Atherosclerosis, 219: 280-284.

22. Krasimir K, Lyudmila H (2018): Role of Magnesium Deficiency in Promoting Atherosclerosis, Endothelial Dysfunction, and Arterial Stiffening as Risk Factors for Hypertension. Int J Mol Sci., 19 (6): 1724.

23. Baby B, Gupta D (2018): A study of lipid profile and its correlation between magnesium in non-diabetic chronic kidney disease patients on hemodialysis. Int $\mathbf{J}$ of Applied Res., 4 (3): 329-332

24. Nassiri A, Hakemi M (2013): Serum Magnesium Level and cardiovascular Disease in Dialysis Patients, Iran J Kidney Dis., 7 (1): 88.

25. Tony E, Tohamy M, Amin N et al. (2017): Correlations of serum magnesium with dyslipidemia in patients on maintenance hemodialysis. J Egypt Soc Nephrol Transplant., 17 (1): 8.

26. Liu F, Zhang X, Qi H et al. (2013): Correlation of serum magnesium with cardiovascular risk factors in maintenance hemodialysis patients, a cross-sectional study. Magnes Res., 26 (3): 100-8.

27. Ari E, Kaya Y, Demir H et al. (2011): The correlation of serum trace elements and heavy metals with carotid artery atherosclerosis in maintenance hemodialysis patients. Biol Trace Elem Res., 144: 351-359.

28. Falaknazi K, Tajbakhsh R, Sheikholeslami F et al. (2012): Evaluation of Association between Intima-Media Thickness of the Carotid Artery and Risk Factors for Cardiovascular Disease in Patients on Maintenance Hemodialysis. Saudi J Kidney Dis Transpl., 23 (1): 31-36

29. Zhou Q, Tian J, Chen J et al. (2012): Accumulation of circulating advanced oxidation protein products is an independent risk factor for ischemic heart disease in maintenance hemodialysis patients. Nepherol., 17 (7): 642-649. 